\title{
Análise econômica da terminação de bovinos de corte em confinamentos no estado de Minas Gerais: estudo de caso ${ }^{1}$
}

\author{
Marcos Aurélio Lopes², Angelo Dias Brito Ribeiro ${ }^{3}$, Tatiane Mendonça Nogueira \\ Andréia Alves Demeu ${ }^{5}$, Fabiano Alvim Barbosa ${ }^{6}$
}

\section{RESUMO}

Objetivou-se, com este trabalho, estudar a rentabilidade da terminação de bovinos de corte em confinamento. Especificamente, pretendeu-se, ainda, identificar os componentes dos custos total e operacional efetivo, que foram mais relevantes no custo da arroba de carne produzida e estimar o ponto de equilíbrio. A coleta de dados foi de janeiro a dezembro de 2009 , em dois sistemas de produção de bovinos de corte, localizados em Sete Lagoas - MG (confinamento 1) e Carmo de Minas MG (confinamento 2). O processamento eletrônico dos dados e a análise de rentabilidade foram realizados, utilizando-se o software Cu\$to Bovino Corte ${ }^{\circledR}$, considerando-se a margem bruta, a margem líquida e o resultado (lucro ou prejuízo) como indicadores de eficiência econômica. O confinamento 1 não apresentou viabilidade econômica, mas obteve margens líquida e bruta positivas, o que indica que a atividade pode sobreviver no curto e médio prazos; o confinamento 2, por apresentar margens bruta e líquida e resultado positivos, demonstra que a atividade tem possibilidade de manter-se no longo prazo e com possibilidade de expansão. Os itens que apresentaram maiores representatividades sobre o custo total da atividade foram, em ordem decrescente, para o confinamento 1: aquisição de animais, alimentação, mão de obra e depreciação; e, para o confinamento 2: aquisição de animais, alimentação, despesas diversas (aluguel de máquinas, principalmente) e depreciação. Em relação ao custo operacional efetivo, foram, em ordem decrescente, aquisição de animais, alimentação, mão de obra e energia; aquisição de animais, alimentação, despesas diversas (aluguel de máquinas, principalmente) e mão de obra, para os confinamentos 1 e 2 , respectivamente.

Palavras-chave: custo de produção, lucratividade, pecuária de corte.

\section{ABSTRACT}

\section{Economic analysis of the finishing of beef cattle in feedlots in the state of Minas Gerais: a case study}

The objective of this study was to evaluate the profitability of the beef cattle finishing in feedlot. Particularly, it was also intended to identify the components of the total and effective operational cost of greater impact on the production of meat and estimate the breakeven point. Data collection was carried out from January to December of 2009 in two beef cattle production systems, located in Sete Lagoas - MG (feedlot 1) and Carmo de Minas - MG (feedlot 2). The electronic data processing as well as the profitability analysis were conducted using the Cu\$to Bovino Corte ${ }^{\circledR}$ software, considering the gross margin, the net margin and the result (either profit or loss) as economic efficiency indicators. Feedlot 1 showed positive net and gross margins, which points out that it can survive in the short and medium term;

\footnotetext{
Recebido para publicação em 13/08/2012 e aprovado em 29/04/2013.

'Pesquisa financiada pela FAPEMIG (FAPEMIG CVZ - APQ-00607-08).

${ }^{2}$ Licenciado em Ciências Agrícolas, Doutor. Departamento de Medicina Veterinária, Universidade Federal de Lavras, Caixa Postal 3037, 37200-000, Lavras, Minas Gerais, Brasil. malopes@dmv.ufla.br (autor para correspondência). Bolsista do CNPq.

${ }^{3}$ Graduando em Zootecnia. Departamento de Medicina Veterinária, Universidade Federal de Lavras, Caixa Postal 3037, 37200-000, Lavras, Minas Gerais, Brasil. angelodiasb@hotmail.com (Bolsista de Iniciação científica CNPq/PIBIC).

${ }^{4}$ Graduanda em Medicina Veterinária. Departamento de Medicina Veterinária, Universidade Federal de Lavras, Caixa Postal 3037, 37200-000, Lavras, Minas Gerais, Brasil. tati.mn@ hotmail.com (Bolsista da FAPEMIG).

5Zootecnista. Departamento de Medicina Veterinária, Universidade Federal de Lavras, Caixa Postal 3037, 37200-000, Lavras, Minas Gerais, Brasil. andreiademeu@hotmail.com (Bolsista CAPES).

${ }^{6}$ Médico Veterinário, Doutor. Departamento de Zootecnia, Escola de Veterinária da Universidade Federal de Minas Gerais, Avenida Antônio Carlos, 6627, Campus da UFMG, 30123970, Belo Horizonte, Minas Gerais, Brasil. fabianoalvimvet@hotmail.com
} 
feedlot 2 , showed gross and net margins and positive result, which demonstrates that the activity has the possibility of being suatainable in the long term and possibility of expanding. The items which showed greatest representativeness on the total cost of the activity for feedlot 1 were, in decreasing order, purchase $o$ animals, feeding, labor and depreciation; and for feedlot 2, purchase of animals, feeding, sundry expenses (rental of machinery, especially) and depreciation. Regarding the effective operational cost, the items, in decreasing order, were purchase of animals, feeding, labor and energy for feedlot 1; and purchase of animals, feeding, sundry expenses(rental of machinery, especially) and labor, for feedlot 2 .

Key words: beef cattle, production cost, profitability.

\section{INTRODUÇÃO}

Na atual circunstância de globalização, em que se encontra a sociedade, mudanças frequentes vêm ocorrendo na perspectiva de adaptação a essa nova realidade de um mercado cada vez mais competitivo. Também no âmbito do agronegócio, há a necessidade de se inserir nesse novo contexto. Para isso, é necessário, por parte do produtor rural, encarar sua propriedade como uma empresa, abandonando antigos costumes herdados de seus pais e avós, admitindo uma nova realidade e adquirindo uma postura de empresário, buscando uma maior rentabilidade e produtividade para sua empresa. Sendo assim, ele deve se ater à importância de uma boa administração e da análise econômica de sua empresa, pois a partir daí passará a conhecer melhor sua empresa e, com isso, a fazer melhor uso de seus recursos e tomar decisões com maior segurança e confiabilidade nos resultados.

A atividade do setor agrícola, seja qual for, deve ser continuamente avaliada sob o âmbito econômico, para se manter competitiva. Citam-se, como fatores imprescindíveis para o sucesso de qualquer sistema de produção, o conhecimento dos custos de produção da atividade, a lucratividade obtida e a rentabilidade do capital investido. Essa análise permite a identificação do item que, em determinado momento, poderá inviabilizar a atividade, como as oscilações de preço do mercado (Peres \& Souza, 2005). Segundo Lopes \& Carvalho (2002), os dados obtidos na apuração dos custos de produção têm sido utilizados para diferentes finalidades, tais como: estudo da rentabilidade da atividade, redução dos custos controláveis, planejamento e controle das operações do sistema de produção, identificação e determinação da rentabilidade do produto, identificação do ponto de equilíbrio do sistema de produção e instrumento de apoio ao produtor no processo de tomada de decisões seguras e corretas.

Os pecuaristas tem-se preocupado em intensificar os ganhos nos sistemas de produção, geralmente, por meio de adequações e melhorias no manejo e alimentação dos animais. E, muitas vezes, não percebem que se utilizando dos bens existentes na propriedade, em sua totalidade, haverá uma redução no custo de produção e, com isso, um aumento da produtividade, sem diminuir a sua lucratividade.

Alguns pesquisadores tem-se atentado em estimar o custo de produção e a viabilidade econômica da produção de carne bovina nos variados sistemas de produção (Cezar e Euclides Filho, 1996; Alves et al., 1999; Potter et al., 2000; Aguiar et al., 2001; Bueno et al., 2004). Contudo, esses pesquisadores não apontaram quais fatores influenciaram o custo e quais componentes exerceram maior influência.

Por falta de informações que associem a produção e o custo de produção de bovinos de corte em confinamento, objetivou-se, com este trabalho, a realização desta pesquisa, a fim de avaliar a rentabilidade da pecuária de corte em regime de confinamento. Pretendeu-se, ainda, identificar os componentes dos custos total e operacional efetivo, que exerceram maior representatividade na produção da arroba de carne e estimar o ponto de equilíbrio do sistema de produção.

\section{MATERIAL E MÉTODOS}

O período de coleta de dados foi de janeiro a dezembro de 2009 (12 meses), nos dois sistemas de produção, que desenvolviam a atividade de terminação de bovinos de corte em confinamento. O confinamento 1, localizado no município de Sete Lagoas - MG, realizou a terminação dos animais de junho a outubro (cinco meses). No entanto, houve entrada e saída de animais, em períodos diferentes, e a duração média de cada ciclo foi de 76 dias. O rebanho era constituído por garrotes e vacas Nelore (662), e garrotes (Angus x Nelore (95)), adquiridos de rebanhos comerciais. O confinamento 2, localizado em Carmo de Minas, MG, realizou a terminação de julho a outubro de 2009 (4 meses). O rebanho foi constituído por novilhos (277) e vacas (49) de composição racial 5/8 Holandês $3 / 8 \mathrm{Gir}$, adquiridos também de rebanho comercial.

A pesquisa considerou duas etapas no levantamento das informações: na primeira, utilizando-se um questionário e caderneta de campo, foi realizado o inventário completo dos bens dos sistemas de produção estudados, apurandose valor e vida útil de cada ativo, posteriormente, alocados em um dos seguintes grupos: benfeitorias, máquinas, veículos, rebanho, animais de tração, equipamentos, implementos 
e ferramentas. Nas situações, nas quais o pecuarista não dispunha de informações referentes ao valor e data de aquisição, para a estimativa dos valores atuais, bem como da vida útil restante, foi adotado o critério proposto por Lopes et al. (2004a). Para as benfeitorias, cada uma foi medida, sendo atribuído um estado de conservação, objetivando auxiliar na estimativa do valor atual. Em função da área, do estado de conservação e do padrão de acabamento, estimou-se um valor por $\mathrm{m}^{2}$ de construção. $\mathrm{O}$ valor atual utilizado foi produto do valor do $\mathrm{m}^{2}$ pela área da benfeitoria (Lopes et al., 2004b).

$\mathrm{Na}$ segunda etapa, os sistemas de produção foram visitados para coleta de dados referentes às despesas realizadas e às receitas apuradas. A coleta deu-se em cadernetas de campo preparadas especificamente para esse fim. Esses dados foram cadastrados no software Cu\$to Bovino Corte ${ }^{\circledR}$ (Lopes et al., 2003), aplicativo utilizado para o processamento dos dados, bem como para a análise de rentabilidade. Esse aplicativo contempla as duas estruturas de custo de produção: custo total de produção, que envolve o custo fixo (depreciação; impostos considerados fixos, como IPVA e ITR; remuneração da terra; remuneração do capital investido; e remuneração do empresário) e variável (desembolsos com mão de obra, alimentação e demais insumos; e remuneração do capital de giro), e custo operacional total, que é composto pela soma do valor referente à depreciação, mão de obra familiar e custo operacional efetivo (que representa os desembolsos com mão de obra, alimentação e demais insumos utilizados no processo produtivo). Como indicadores de rentabilidade, consideraram-se a margem bruta (receita menos custo operacional efetivo (COE)), a margem líquida (receita menos custo operacional total (COT)) (Matsunaga et al.,1976) e o resultado (receita menos custo total) (Barros, 1948).

A finalidade de se utilizar as duas metodologias de custo de produção (custo operacional total e custo total) deve-se à importância dos três indicadores de eficiência econômica: margem bruta, margem líquida (estimados pela metodologia do custo operacional) e resultado (estimado pela metodologia do custo total), que serão úteis nas tomadas de decisões em curto, médio e longo prazos, respectivamente.

Além desses, estimaram-se, ainda, a lucratividade 1, que foi calculada como sendo o resultado dividido pela receita total (Lucratividade $1(\%)=$ Resultado/Receita total); a rentabilidade 1, obtida pela divisão do resultado pelo total imobilizado mais o custo operacional efetivo (Rentabilidade 1 $(\%)=$ Resultado/(Total imobilizado + Custo operacional efetivo). Como lucratividade 2 , considerou-se a divisão da margem líquida pela receita total (Lucratividade $2(\%)=$ Margem líquida/Receita total); e, como rentabilidade 2, considerouse a divisão da margem líquida pelo total imobilizado mais o custo operacional efetivo (Rentabilidade $2(\%)=$ Margem líquida/(Total imobilizado + Custo operacional efetivo)). Es- ses dois últimos indicadores foram estimados segundo Lopes et al. (2011). Os recursos de capital fundiário e permanente, utilizados para a produção das arrobas estão apresentados na Tabela 1.

A pesquisa foi desenvolvida utilizando-se o conceito de estudo de caso, descrito por Yin (2008). Os dados foram agrupados em tabelas, objetivando melhor apresentação, comparação e discussão dos resultados.

\section{RESULTADOS E DISCUSSÃO}

$\mathrm{Na}$ análise de rentabilidade da atividade pecuária de corte, nos dois confinamentos estudados (Tabela 2), as receitas foram oriundas principalmente da venda de todos os animais dos sistemas de produção, o que representou aproximadamente 99,30 e 99,80\% da receita; e pela produção de esterco, que foi comercializado, com participação de 0,70 e $0,20 \%$ para os confinamentos 1 e 2, respectivamente. Esse percentual está aquém dos obtidos por Lopes e Sampaio (1999), 6,8\%; Martins et al. (2002), 3,3\%; Martins e Lopes (2002), 2,6\%; e Lopes et al. (2007), 7,3\%. No entanto, o confinamento 1 utilizou o esterco como adubo para produção de volumoso, e sua participação percentual concorda com a observada por Lopes \& Magalhães (2005b), que encontraram valores $0,53 \%$ para venda de esterco, pois grande parte foi utilizada como adubo nas capineiras. Segundo Lopes et al. (2004b), o fato de ser utilizado no próprio sistema de produção, como adubo orgânico, embora, em um primeiro momento, signifique redução da receita, representou também uma redução nas despesas com manutenção das capineiras. O baixo aproveitamento do esterco no confinamento 2 pode ser explicado pelo maior volume de chuvas no período efetivo de confinamento, ocorrendo a perda de grande parte. Porém, o valor encontra-se muito abaixo, pois o confinamento não utiliza o esterco para adubação de lavouras, já que toda a alimentação é adquirida de terceiros. Esse fato evidencia que se deve dar atenção a esse subproduto, que pode melhorar ainda mais o resultado da atividade, e, em alguns casos, pode tornar o resultado da atividade positivo. A diferença das receitas entre os confinamentos é devida à diferença de escala de produção, que existe entre eles, aliada a ganho de peso médio diário e valor da arroba.

O confinamento 2 apresentou melhor ganho de peso médio diário (GPMD), de 1,263kg, quando comparado ao confinamento 1 , cujo ganho foi de $1,164 \mathrm{~kg}$. Tais ganhos podem ser justificados pelos pesos de entrada dos animais nos confinamentos, pois os animais que entraram mais leves (confinamento 2) podem ser animais mais jovens, apresentando maior potencial de ganho de peso. Na Tabela 3, observa-se que os animais do confinamento 1 saíram com $1,74 @$ a mais que os do confinamento 2 , o que representa, pelo peso dos animais na entrada, que esses animais já estavam próximos ao período de deposição de gordura na carcaça , a qual é, segundo Berg e Butterfield (1976), mais cara e mais lenta. 
O valor de venda das arrobas variou entre os dois confinamentos (Tabela 2), interferindo negativamente no resultado do confinamento 1 . Nem mesmo a maior produção de arrobas favoreceu o confinamento 1 . O confinamento 2 pode ter levado uma vantagem por ter feito contrato de venda com o frigorífico, garantindo assim um melhor valor na arroba.
O custo operacional total, que foi composto apenas pela soma do custo operacional efetivo e depreciação (pois a mão de obra foi toda contratada; portanto, sem participação de mão de obra familiar), foi diferente entre os dois confinamentos (Tabela 2). Os valores, em percentagem, da depreciação de 1,8 e 0,82\% para os confinamentos 1 e 2 , respectivamente, foram bem diferentes, o que se justifica

Tabela 1. Recursos disponíveis em dois confinamentos de gado de corte, no Estado de Minas Gerais, no período de janeiro de 2009 a dezembro de 2009

\begin{tabular}{|c|c|c|c|c|}
\hline \multirow{3}{*}{ Especificação } & \multicolumn{4}{|c|}{ Confinamento } \\
\hline & 1 & 2 & 1 & 2 \\
\hline & \multicolumn{2}{|c|}{$(\mathbf{R} \$)$} & \multicolumn{2}{|c|}{$(\%)$} \\
\hline Valor do patrimônio em terra & $110.884,60$ & $5.000,00$ & 35,78 & 7,25 \\
\hline Valor do patrimônio sem terra & $199.011,02$ & $63.975,00$ & 64,22 & 92,75 \\
\hline Valor em benfeitorias & $115.709,33$ & $18.391,00$ & 37,34 & 26,66 \\
\hline Valor em equipamentos/ ferramentas/implementos & $27.909,18$ & $45.584,00$ & 9,01 & 66,09 \\
\hline Valor em máquinas & $55.392,51$ & 0,00 & 17,87 & 0,00 \\
\hline Total imobilizado $(\mathrm{R} \$)$ & $309.895,62$ & $68.975,00$ & - & - \\
\hline Valor imobilizado sem terra/ ha $(\mathrm{R} \$)$ & $101.169,19$ & $63.975,00$ & - & - \\
\hline Total imobilizado em terra/ha (R\$) & $5.666,05$ & $5.000,00$ & - & - \\
\hline Área (ha) & 19,57 & 1,00 & & \\
\hline
\end{tabular}

Tabela 2. Resumo da análise de rentabilidade da atividade pecuária de corte (em dois confinamentos, no Estado de Minas Gerais, no período de janeiro a dezembro de 2009

\begin{tabular}{|c|c|c|}
\hline \multirow{2}{*}{ Especificação } & \multicolumn{2}{|c|}{ Confinamento } \\
\hline & 1 & 2 \\
\hline Receitas $(\mathrm{R} \$)$ & $1.000 .837,03$ & $423.491,64$ \\
\hline Custo operacional total $(\mathrm{R} \$)$ & $988.502,03$ & $377.549,92$ \\
\hline Custo operacional efetivo (R\$) & $970.608,70$ & $374.455,47$ \\
\hline Custo com depreciação (R\$) & $17.893,33$ & $3.094,45$ \\
\hline Custo total $(\mathrm{R} \$)$ & $1.021 .381,34$ & $386.100,45$ \\
\hline Custos fixos $(\mathrm{R} \$)$ & $34.338,13$ & $6.283,12$ \\
\hline Remuneração da terra $(\mathrm{R} \$)$ & $4.524,19$ & 231,12 \\
\hline Remuneração sobre o capital investido (R\$) & $11.940,66$ & $2.898,18$ \\
\hline Custo com impostos $(\mathrm{R} \$)$ & 29,95 & 59,37 \\
\hline Custo com depreciação (R\$) & $17.893,33$ & $3.094,45$ \\
\hline Custos variáveis $(\mathrm{R} \$)$ & $986.993,21$ & $379.817,33$ \\
\hline Custo operacional efetivo sem impostos (R\$) & $970.578,75$ & $374.396,10$ \\
\hline Remuneração sobre o capital de giro $(\mathrm{R} \$)$ & $16.414,46$ & $5.421,23$ \\
\hline Margem bruta $(\mathrm{R} \$)$ & $30,228,33$ & $49.036,17$ \\
\hline Margem líquida (R\$) & $12.355,00$ & $45.941,72$ \\
\hline Resultado (R\$) & $-20.544,31$ & $37.391,19$ \\
\hline Lucratividade1 (\%) & $-2,05$ & 8,83 \\
\hline Rentabilidade1 (\%) & $-1,60$ & 8,43 \\
\hline Lucratividade2 (\%) & 1,23 & 10,85 \\
\hline Rentabilidade2 (\%) & 0,96 & 10,36 \\
\hline Custo operacional total/arroba (R\$) & 75,04 & 72,57 \\
\hline Custo operacional efetivo/arroba (R\$) & 73,68 & 73,17 \\
\hline Custo total/arroba $(\mathrm{R} \$)$ & 77,53 & 74,83 \\
\hline Custo variável unitário/arroba (R\$) & 74,92 & 73,61 \\
\hline Custo fixo / arroba (R\$) & 2,61 & 1,22 \\
\hline Preço médio @ (R\$) & 75,41 & 81,90 \\
\hline
\end{tabular}

1 - Fórmula considerando o resultado da atividade; 2 - Fórmula considerando a margem líquida da atividade.

Rev. Ceres, Viçosa, v. 60, n.4, p. 465-473, jul/ago, 2013 
pelo fato de o confinamento 1 incluir máquinas, equipamentos, caminhão e fábrica de ração, enquanto o confinamento 2 não os inclui, já que compra toda sua alimentação de terceiros e aluga tratores para o serviço, o que pode ser um alternativa para os confinamentos, uma vez que houve menor representatividade da depreciação no confinamento que alugou as máquinas e adquiriu de terceiros a alimentação. A depreciação poderia ser menor, no confinamento 1 , caso o pecuarista realizasse outro ciclo, ou seja, confinasse mais animais no decorrer do ano, para otimizar o uso das máquinas, ferramentas, implementos, veículos e benfeitorias. Lopes \& Magalhães (2005b) verificaram que a depreciação foi responsável por $0,56 \%$ do custo operacional total; Moreira et al. (2009), 1,05\%; Lopes \& Sampaio (1999), 3,84\%; 1,92 e $1,12 \%$, em confinamentos de 100,500 e 1.000 cabeças, respectivamente; e Lopes \& Magalhães (2005a), 1,74\%. Embora não se tenha dados de referência na literatura sobre qual o valor ideal para esse indicador, pode-se observar, neste trabalho, que os valores encontrados pelo confinamento 1 indicam que a eficiência de utilização de máquinas, equipamentos e benfeitorias foi semelhante ao valor encontrado por Lopes \& Magalhães (2005a); superiores aos encontrados por Moreira et al. (2009) e Lopes \& Magalhães (2005b); e inferiores aos encontrados por Lopes \& Sampaio (1999), em confinamentos de 100 e próximo ao de 500 cabeças. No entanto, o confinamento 2 mostrou menor eficiência, na utilização de seus bens, apenas em relação ao valor encontrado por Lopes e Magalhães (2005b).

O custo operacional efetivo (COE), que representa o desembolso médio no período, feito por cada empresário, para custear a atividade, foi maior no confinamento 1 por causa da maior quantidade de animais confinados (Tabela 2). Os itens que compõem o COE foram divididos em grupos (Tabela 4). A divisão das despesas em grupos, de acordo com Lopes e Lopes (1999), permite o monitoramento das despe- sas do sistema de produção, auxiliando o técnico e o produtor em uma análise mais detalhada. O item com maior representatividade foi aquisição de animais, nos dois confinamentos. Lopes \& Sampaio (1999), Lopes \& Magalhães (2005a), Lopes \& Magalhães (2005b), Lopes et al. (2007) e Restle et al. (2007) também responsabilizaram esse item pela maior representatividade do COE. Lopes \& Magalhães (2005a) enfatizam que o alto percentual deve ser observado pelo pecuarista com maior atenção, pois uma pequena economia, sem desconsiderar a qualidade dos animais a serem confinados, representa redução considerável do COE, que reflete na lucratividade e na rentabilidade.

A alimentação foi o item com a segunda maior representatividade no $\mathrm{COE}$, pois na produção de bovinos de corte em regime de confinamento, há um maior dispêndio de recursos diretos, quando comparados com o dispêndio da produção a pasto, porque o alimento concentrado é a principal fonte de nutrientes e apresenta alto valor de compra. A representatividade da alimentação foi de 15,66 e 26,65\%, para os confinamentos 1 e 2 , respectivamente. $\mathrm{O}$ fato de $\mathrm{o}$ confinamento 1 produzir o volumoso utilizado na alimentação dos animais confinados, e ser esse volumoso a cana-deaçúcar, que produz maior quantidade de matéria seca por hectare, quando comparada com a da silagem de milho, o qual foi comprado pelo confinamento 2 , pode explicar uma redução significativa nos gastos com alimentação. $\mathrm{O}$ valor referente à formação do canavial foi contabilizado no inventário, já que a vida útil dele é maior do que um ciclo produtivo. Assim, esse valor foi considerado na depreciação, bem como na remuneração do capital investido. Quanto ao valor de manutenção do canavial, como as adubações de manutenção, ele foi computado no item alimentação. Outro fator importante para essa diferença foi o preço do milho, principal fonte de energia utilizada na alimentação nos dois confinamentos $(\mathrm{R} \$ 0,267 / \mathrm{kg}$ no confina-

Tabela 3. Dados de compra, venda e ganho de peso em dois confinamentos no Estado de Minas Gerais, no período de janeiro a dezembro de 2009

\begin{tabular}{|c|c|c|c|c|c|c|}
\hline \multirow{3}{*}{ Categoria } & \multicolumn{6}{|c|}{ Confinamento } \\
\hline & 1 & 2 & 1 & 2 & 1 & 2 \\
\hline & \multicolumn{2}{|c|}{ Quantidade de animais } & \multicolumn{2}{|c|}{ Peso médio (@ )* } & \multicolumn{2}{|c|}{ Peso total $(@)^{*}$} \\
\hline \multicolumn{7}{|c|}{ Compra de animais } \\
\hline Novilhos & 648 & 277 & 14,79 & 11,41 & $9.586,86$ & $3.161,07$ \\
\hline Vacas & 109 & 49 & 12,46 & 12,91 & $1.358,14$ & 632,68 \\
\hline Total & 757 & 326 & - & - & $10.945,00$ & $3.793,75$ \\
\hline \multicolumn{7}{|l|}{ Venda de animais } \\
\hline Novilhos & 645 & 275 & 17,92 & 16,18 & $11.558,11$ & $4.450,08$ \\
\hline Vacas & 109 & 49 & 14,82 & 14,48 & $1.615,39$ & 709,53 \\
\hline Total & 754 & 324 & - & - & $13.173,50$ & $5.159,61$ \\
\hline Ganho de peso@ & & & 2,95 & 4,21 & $2.228,50$ & $1.365,86$ \\
\hline
\end{tabular}

*Considerou-se rendimento de carcaça de 50\% 
mento 1 e $\mathrm{R} \$ 0,333 / \mathrm{kg}$ no 2). Valor não muito distante do encontrado no confinamento 1 foi encontrado por Moreira et al. (2009), 19,19\%, e valor não muito distante do encontrado no confinamento 2 foi encontrado por Lopes et al. (2005a), $24,81 \%$. No entanto, juntamente com os valores encontrados por Lopes et al. (2007), de 20,97, 21,56 e 21,78\%, para confinamentos com 100, 500 e 1000 animais, respectivamente, e Lopes \& Magalhães (2005a), são valores intermediários aos encontrados pelos dois confinamentos. Porém, valores maiores foram encontrados por Lopes \& Sampaio (1999), 29,84\%, Lopes \& Magalhães (2005b), 30,25\% e Ferreira et al. (2009), 40,23\%. O custo com alimentação poderia ser reduzido com contratos de compra antecipados de alimentos, utilização de coprodutos e alimentos alternativos, considerando-se que esses sofrem variações nos anos, e dietas de custo mínimo com a ajuda de softwares desenvolvidos especificamente para esse fim.

No confinamento 1 , o item com a terceira maior representatividade foi mão de obra e, no 2 , despesas diversas (manutenção de benfeitorias, fretes e aluguel de trator, principalmente). A maior representatividade da mão de obra no confinamento 1 pode ser explicada pela menor relação animal/homem (2,5 vezes menor) (Tabela 5), quando comparada com a do confinamento 2 ; isso mostra que o confinamento 2 foi mais eficiente na utilização desse recurso. Esse peso da mão de obra pode ter sido maior por causa, também, da necessidade do confinamento 1 para a produção do volumoso. No entanto, observa-se que o confinamento 2 otimiza seus recursos. Já a maior representatividade das despesas diversas, no confinamento 2, justifica-se pelos gastos com aluguel de trator.

Ao analisar o COE por arroba, que é por onde se pode realmente comparar os dois confinamentos, verifica-se que são bastante semelhantes: no confinamento 1 (R $\$ 73,63)$; no 2 (R $\$ 73,17)$. Mesmo com o valor da arroba um pouco menor ( $\mathrm{R} \$ 69,17$, para o confinamento 1 e $\mathrm{R} \$ 70,00$, para o 2) e a principal fonte de energia, utilizada na alimentação, nos confinamentos, também de valor mais baixo, e maior produção de arrobas no confinamento 1, tem-se maior valor nos COE unitário (por arroba) e custo operacional total (COT) unitário (Tabela 2). Com isso, nem mesmo a maior produção de arrobas, no confinamento 1, influenciou os COE unitário e COT unitário, o que pode ser explicado pelo maior gasto na compra de animais, que foi o item com maior representatividade, maior gasto com mão de obra e também o menor GPMD, o que acarretou maior quantidade de dias dos animais em confinamento e, com isso, maior gasto com alimentação, já que os animais saíram do confinamento com quase 18@ (Tabela 3), podendo-se reduzir esses custos com a saída dos animais um pouco mais leves.

Os custos totais (CT), que representam a soma dos custos variáveis (CV) e custos fixos (CF), foram diferentes nos dois confinamentos (Tabela 4), em razão, principalmente, da escala de produção. Os itens que mais impactaram o CT foram aquisição de animais e alimentação, para os confinamentos 1 e 2 , seguidos de mão de obra e depreciação, para o confinamento 1, e de despesas diversas e remuneração do capital investido, para o confinamento 2 (Tabela 6).

Dentre os CF, a remuneração da terra, a remuneração sobre o capital investido, os impostos, considerados fixos (IPVA e ITR) e a depreciação do patrimônio não representam o desembolso por parte do empresário rural, exceto os impostos fixos, mas devem ser considerados, pois representam o que a atividade deveria remunerar para ser comparada com outras atividades. $\mathrm{O}$ item com maior representatividade foi a depreciação, seguido da remuneração do capital investido, para os dois confinamentos (Tabela 6). Deve-se considerar esses custos para que não haja a descapitalização do produtor. Se não forem contemplados, o pecuarista poderá, em longo prazo, perder o patrimônio e se endividar (Lopes et al., 2006). Ao se analisar a influência do CF no CT, quando se considera a aquisição de animais, tem-se $3,37 \%$ para o confinamento 1 e $1,63 \%$ para o confinamento 2 . Esse maior

Tabela 4. Contribuição de cada item no custo operacional efetivo em dois confinamentos no Estado de Minas Gerais, no período de janeiro a dezembro de 2009 , em \%

\begin{tabular}{|c|c|c|c|c|}
\hline \multirow{3}{*}{ Especificação } & \multicolumn{4}{|c|}{ Confinamento } \\
\hline & \multicolumn{2}{|c|}{1} & \multicolumn{2}{|c|}{2} \\
\hline & $\operatorname{CAA}(\%)$ & NAA $(\%)$ & CAA $(\%)$ & $\operatorname{NAA}(\%)$ \\
\hline Aquisição de animais & 78,00 & - & 70,06 & - \\
\hline Alimentação & 15,66 & 71,13 & 26,65 & 89,03 \\
\hline Mão de obra & 5,13 & 23,33 & 0,63 & 2,09 \\
\hline Sanidade & 0,43 & 1,97 & - & - \\
\hline Energia & 0,78 & 3,56 & - & - \\
\hline Despesas diversas & 0,00 & 0,00 & 2,64 & 8,83 \\
\hline Impostos & 0,00 & 0,01 & 0,02 & 0,05 \\
\hline Total do COE & 100,00 & 100,00 & 100,00 & 100,00 \\
\hline
\end{tabular}

$\overline{\mathrm{CAA}}=$ considerando aquisição de animais; NAA = não considerando a aquisição de animais.

Rev. Ceres, Viçosa, v. 60, n.4, p. 465-473, jul/ago, 2013 
valor para o confinamento 1 é devido à maior quantidade de benfeitorias, máquinas e equipamentos, que esse sistema de produção apresenta, já que produz seu alimento volumoso e processa seu concentrado, enquanto o confinamento 2 aluga suas máquinas. No entanto, os valores encontrados nesses confinamentos estão melhores que os encontrados por Lopes et al. (2005a), 4,58\%, Ferreira et al. (2009), 7,2\%; e mais expressivos que o valor encontrado por Lopes \& Magalhães (2005b), 1,13\%.

A remuneração da terra, que, em muitos casos, na pecuária de corte, por causa da grande área demandada, tem alto valor de influência no CF, não apresentou o mesmo comportamento. A diferença entre os dois confinamentos (Tabela 6) é decorrente da área destinada ao confinamento. Foi utilizado para definir a remuneração da terra o preço do litro de leite. O confinamento 1, por produzir seu volumoso, necessita de área maior para o sistema como um todo, enquanto o 2 adquire todo o alimento de terceiros, o que explica a área reduzida. Ainda, não há maquinário, já que foi alugado um trator e, desse modo, essa despesa foi lançada em despesas diversas. Essa é uma questão que deve ser levada em consideração, a produção ou não do alimento, pois quando produzido com eficiência pode favorecer a rentabilidade da empresa e, o contrário, pode inverter essa situação.

Nestas circunstâncias, a compra de alimentos está sendo vantajosa, já que a lucratividade e a rentabilidade do confinamento 2 foram bem superiores às do confinamento 1 . Porém, melhor lucratividade e melhor rentabilidade podem não estar diretamente ligadas à produção do volumoso, mas, indiretamente, ao aumento necessário de terra, máquinas,

Tabela 5. Índices técnicos/gerenciais e econômicos de dois confinamentos no Estado de Minas Gerais, no período de janeiro a dezembro de 2009 , em $\%$

\begin{tabular}{lrr}
\hline \multirow{2}{*}{ Índices técnicos/gerenciais } & \multicolumn{1}{c}{ Confinamento } \\
\cline { 2 - 3 } & 46,22 & $\mathbf{2}$ \\
\hline Taxa de lotação (UA/ha) & $13.173,50$ & 343,97 \\
Quantidade de arroba produzida & 673,15 & $5.159,61$ \\
Produção de arroba/área (@/ha/período) & 126,17 & $5.159,61$ \\
Relação animal/homem & $70.317,06$ & 326,00 \\
Ponto de equilíbrio @ & & 758,25 \\
\hline Índices econômicos & 3,37 & 1,63 \\
\hline Custo fixo / Custo total (\%) & 96,63 & 98,37 \\
Custo variável / Custo total (\%) & 1,81 & 0,82 \\
Custo com depreciação / Custo operacional total (\%) & 98,19 & 99,18 \\
Custo operacional efetivo / Custo operacional total (\%) & & \\
\hline
\end{tabular}

Tabela 6. Contribuição de cada item no custo total em dois confinamentos no Estado de Minas Gerais, no período de janeiro de 2009 a dezembro de 2009 , em \%

\begin{tabular}{|c|c|c|c|c|}
\hline \multirow{3}{*}{ Especificação } & \multicolumn{4}{|c|}{ Confinamento } \\
\hline & \multicolumn{2}{|c|}{1} & \multicolumn{2}{|c|}{2} \\
\hline & $\operatorname{CAA}(\%)$ & NAA(\%) & $\operatorname{CAA}(\%)$ & $\mathbf{N A A}(\%)$ \\
\hline Custo fixo (CF) & 3,37 & 13,01 & 1,63 & 5,08 \\
\hline Remuneração da terra & 0,44 & 1,71 & 0,06 & 0,19 \\
\hline Remuneração sobre o capital investido & 1,17 & 4,52 & 0,75 & 2,34 \\
\hline Depreciação & 1,76 & 6,77 & 0,80 & 2,50 \\
\hline Imposto & 0,00 & 0,01 & 0,02 & 0,05 \\
\hline Custo variável (CV) & 96,63 & 86,99 & $\mathbf{9 8 , 3 7}$ & 94,92 \\
\hline Aquisição de animais & 74,12 & - & 67,95 & - \\
\hline Alimentação & 14,87 & 57,47 & 25,85 & 80,64 \\
\hline Mão de obra & 4,88 & 18,84 & 0,61 & 1,90 \\
\hline Sanidade & 0,41 & 1,59 & - & - \\
\hline Energia & 0,74 & 2,88 & - & - \\
\hline Despesas diversas & 0,00 & 0,00 & 2,56 & 8,00 \\
\hline Remuneração sobre o capital de giro & 1,61 & 6,21 & 1,40 & 4,38 \\
\hline Total $(\mathrm{CF}+\mathrm{CV})$ & 100,00 & 100,00 & 100,00 & 100,00 \\
\hline
\end{tabular}

$\mathrm{CAA}=$ considerando aquisição de animais; NAA = não considerando a aquisição de animais 
mão de obra e capital, o que implicará elevação do custo de outros itens (remuneração da terra, remuneração do capital investido, mão de obra, energia, depreciação e remuneração do capital de giro).

Quanto ao CT unitário, o confinamento 1 apresentou valor 3,61\% acima do valor no confinamento 2 . Essa pequena diferença é reflexo dos $\mathrm{CV}$ unitário e $\mathrm{CF}$ unitário mais altos que os do confinamento 2. Ao se analisar o CV (que se difere do COE pelo acréscimo da remuneração do capital de giro e exclusão de alguns impostos considerados fixos, como IPVAe ITR), observa-se maior percentual no gasto com compra de animais, que é o item com a maior representatividade, e o gasto com mão de obra, que pode ter influenciado esse maior valor do CV unitário.

As margens brutas, que são as receitas menos o COE, foram positivas nos dois confinamentos, demonstrando que a atividade tem possibilidade de se manter no curto prazo. Isso demonstra, portanto, que a atividade está conseguindo pagar o que o empresário precisou gastar para que a atividade pudesse se desenvolver. As margens líquidas, que são as receitas menos o COT, também foram positivas nos dois confinamentos, mostrando que a atividade está se remunerando, mantendo-se, portanto, no médio prazo e com possibilidade de expansão (Tabela 2). Os resultados, que são as diferenças entre as receitas e o CT (custo variáveis e fixos), foram positivos apenas no confinamento 2 , evidenciando que a atividade foi lucrativa, o que, de acordo com Lopes \& Carvalho (2002), significa que ela se manterá, no longo prazo, possibilitando a capitalização do empresário.

Na lucratividade 1, que representa o lucro obtido na atividade e que pode ser utilizada para comparar atividades semelhantes, observa-se expressiva diferença entre os dois confinamentos, sendo melhor no confinamento 2 (Tabela 2). A rentabilidade 1 representa a capacidade da atividade de gerar rendimentos em relação ao capital investido e pode ser utilizada para comparar atividades diferentes, com o intuito de determinar qual atividade está apresentando maior rendimento para os empresários. Ela também foi maior no confinamento 2. Porém, no cálculo desses índices, leva-se em consideração o resultado da atividade, no qual já está inserido o custo de oportunidade sobre o capital, que representa o retorno que o capital utilizado na atividade estaria rendendo, caso fosse aplicado em outra atividade, no caso a caderneta de poupança. Com isso, mesmo que se obtivesse uma rentabilidade negativa de até $6 \%$, pode-se considerar que a atividade é viável economicamente, já que no resultado foi considerado a remuneração sobre o capital de giro e investido.

Os índices lucratividade e rentabilidade 2 (Lopes et al., 2011) apresentam a mesma função da lucratividade e rentabilidade 1 . No entanto, utilizam como base a margem líquida, o que indica não estar inserido nesses os custos de oportunidade, o que confere a esses índices melhor poder de com- paração e comparação mais adequada da atividade. Assim, ao se analisar o índice lucratividade 2, a atividade passa a ser lucrativa também para o confinamento 1 . Ao se analisar a rentabilidade 2 , vê-se que a atividade apresenta rendimentos para o confinamento 1 , porém não mais atrativos que os da caderneta de poupança. Assim, nesse caso, seria mais interessante (lucrativo) se o produtor optasse por aplicar seu dinheiro na caderneta de poupança. O confinamento 2 apresentou rendimento mais atrativo que o da caderneta de poupança.

A variação do preço da arroba nos dois confinamentos foi expressiva ( $\mathrm{R} \$ 6,49,9,21 \%)$, o que influenciou negativamente o confinamento 1 . Nem mesmo a maior quantidade de animais confinados favoreceu o preço de venda dos animais. E esses valores de venda podem ter sido influenciados pela região e pelos contratos de venda.

Os índices técnicos e gerenciais (Tabela 5) apresentam diferenças entre os dois confinamentos; alguns, por causa da área de cada confinamento (taxa de lotação e produção de arroba/área).

O ponto de equilíbrio não foi alcançado pelo confinamento 1, que seria de 70.317,06@, portanto, seria necessário um aumento de 57.143,56@ para que ele fosse atingido.É possível reduzir o ponto de equilíbrio, quando o pecuarista conseguir diminuir o custo variável unitário e o custo fixo, por meio de melhor utilização de bens e ainda existe a possibilidade de realização de novos ciclos de engorda para redução do custo fixo, ou ainda, de vender os animais por um melhor valor de mercado.

Os índices econômicos custo fixo/custo total e custo com depreciação/custo operacional total apresentam-se maiores no confinamento 1 , principalmente pelo fato de que o confinamento 2 não apresentar muito maquinário, implementos e benfeitorias, ao contrário do 1 .

\section{CONCLUSÕES}

Dentre os sistemas de produção analisados, o confinamento 1 não apresentou viabilidade econômica, mas tem possibilidade de se manter no curto e médio prazos, por apresentar margens bruta e líquida positivas. Por outro lado, o confinamento 2 apresentou viabilidade econômica possibilidade de se manter no curto, médio e longo prazos, com possibilidade de expansão.

Os itens componentes do CT que apresentaram maiores representatividades foram, em ordem decrescente, aquisição de animais, alimentação, mão de obra e depreciação; e aquisição de animais, alimentação, despesas diversas e depreciação, para os confinamentos 1 e 2, respectivamente. Em relação ao COE foram, em ordem decrescente, aquisição de animais, alimentação, mão de obra e energia; e aquisição de animais, alimentação, despesas diversas e mão de obra, para os confinamentos 1 e 2 , respectivamente.. 


\section{REFERÊNCIAS}

Aguiar AP, Almeida BHPJF, Amaral GC, Datena JLF, Younes RJ, Costa RO, Mota J \& Vivan WSO (2001) Viabilidade econômica da produção de carne em sistemas intensivos de pastagens na região do cerrado. In: $38^{\text {a }}$ Reunião Anual da Sociedade Brasileira de Zootecnia, Piracicaba. Anais, SBZ. CD ROM.

Alves JB, Tarsitano MAA, Bergamaschine AF \& Bastos JFP (1999) Desempenho econômico do confinamento de bovinos de diferentes grupos genéticos. In: 36 ${ }^{\mathrm{a}}$ Reunião Anual da Sociedade Brasileira de Zootecnia, Porto Alegre. Anais, SBZ. CD ROM.

Barros H (1948) Economia Agrária. Lisboa, Livraria Sá da Costa. $348 p$.

Berg RT\& Butterfield RM (1976) New concepts of cattle growth. Sidney, Sidney University. 240p.

Bueno PRB, Rorato PRN, Dürr JW \& Krug EEB (2004) Valor econômico para componentes do leite no Estado do Rio Grande do Sul. Revista da Sociedade Brasileira de Zootecnia 33:22562265 .

Cezar IM \& Euclides Filho K (1996) Novilho precoce: reflexos na eficiência e economicidade do sistema de produção. Campo Grande, Embrapa. 31p. (Documento, 66).

Ferreira IC, Silva MA, Barbosa FA, Carvalho ADF, Correa GSS, Fridrich AB \& Souza JER (2009) Avaliação técnica e econômica de diferentes grupos genéticos de bovinos de corte machos superprecoces e o sistema de produção em confinamento. Arquivo Brasileiro de Medicina Veterinária e Zootecnia, 6:143250 .

Lopes MA \& Magalhães GP (2005a) Rentabilidade da terminação de bovinos de corte em confinamento: um estudo de caso em 2003, na região oeste de Minas Gerais. Ciência e Agrotecnologia, 29:1039-1044.

Lopes MA, Magalhães GP (2005b) Análise da rentabilidade da terminação de bovinos de corte em confinamento: um estudo de caso. Arquivo Brasileiro de Medicina Veterinária e Zootecnia, 57:374-379.

Lopes MA, Campello RP, Carvalho FM \& Lopes DCF (2003) Custo Bovino Corte 1.0: software de controle de custos para a pecuária de corte. Ciência e Agrotecnologia, 27:1589-1596.

Lopes MA \& Carvalho FM (2002) Custo de produção do gado de corte. Lavras,UFLA. 47p. (Boletim Agropecuário, 47).

Lopes MA, Lima ALR, Carvalho FM, Reis RP, Santos IC \& Saraiva FH (2004a) Controle gerencial e estudo da rentabilidade de sistemas de produção de leite na região de Lavras (MG). Ciência e Agrotecnologia, 28:883-892.

Lopes MA, Lima ALR, Carvalho FM, Reis RP, Santos IC \& Saraiva FH (2004b) Efeito do tipo de sistema de criação nos resultados econômicos de sistemas de produção de leite na região de Lavras (MG). Ciência e Agrotecnologia, 28:1177-1189.

Lopes MA, Lima ALR, Carvalho FM, Reis RP, Santos IC \& Saraiva FH (2006) Efeito da escala de produção nos resultados econômicos de sistemas de produção de leite na região de Lavras (MG): um estudo multicasos. Boletim Indústria Animal, 63:177-188.

Lopes MA \& Lopes DCF (1999) Desenvolvimento de um sistema computacional para cálculo do custo de produção do leite. Revista Brasileira de Agroinformática, 2:01-12.

Lopes MA, Santos G, Resende MC, Carvalho FM \& Cardoso MG (2011) Estudo da rentabilidade de sistemas de produção de leite na região de Nazareno (MG)6cON. Ciência Animal Brasileira, 12:58-69

Lopes MA \& Sampaio AAM (1999) Manual do confinador de bovinos de corte. Jaboticabal, FUNEP. 106p.
Lopes M A, Santos G, Magalhães GP \& Carvalho FM (2007) Efeito da escala de produção na rentabilidade da terminação de bovinos de corte em confinamento. Ciência e Agrotecnologia, 31:212-217.

Martins FM \& Lopes MA (2002) Análise de rentabilidade de um confinamento de gado de corte realizado no município de Lavras, sul de Minas Gerais. In: $7^{\circ}$ Encontro de Iniciação Científica, Taubaté. Anais, UNITAU. p.94

Martins FM, Macedo SV, Lopes MA (2002) Análise de rentabilidade de um confinamento de gado de corte realizado no município de Ijaci, sul de Minas Gerais. In: $7^{\circ}$ Encontro de Iniciação Científica. Mostra de Pós-graduação UNITAU, Taubaté. Anais. p.94

Matsunaga M, Bemelmans PF \& Toledo PEN (1976) Metodologia de custo de produção utilizado pelo IEA. Agricultura em São Paulo, 23:123-139.

Moreira AS, Thomé KM, Ferreira OS \& Botelho Filho FB (2009) Análise econômica da terminação de gado de corte em confinamento dentro da dinâmica de uma propriedade agrícola. Disponível em: www.custoseagronegocioonline.com.br Acessado em: 06 de dezembro de 2011.

Peres AAC \& Souza PM (2005) Análise econômica de sistemas de produção a pasto para bovinos no município de Campos dos Goytaguases - RJ. Revista da Sociedade Brasileira de Zootecnia, 33:1557-1563.

Potter L, Lobato JFP \& Netto CGAM (2000) Análises econômicas de modelos de produção com novilhas de corte primíparas aos dois, três e quatro anos de idade. Revista da Sociedade Brasileira de Zootecnia, 29:861-870.

Restle J, Pacheco OS, Costa EC \& Freitas AK (2007) Apreciação econômica da terminação em confinamento de novilhos Red Angus superjovens abatidos com diferentes pesos. Revista Brasileira de Zootecnia, 36:978-986.

Yin RK (2008) Case study research: design and methods. Beverly Hills, Sage Publishing. 240p. 